\title{
Answers to be Solved in Training Load Quantification
}

\section{Iker Muñoz*}

Centro de Investigación y Tecnología Industrial de Cantabria, Spain

Health Department, Universidad Europea del Atlántico, Spain

*Corresponding author: Iker Muñoz, PhD, Lecturer \& Researcher, Universidad Europea del Atlántico, Spain

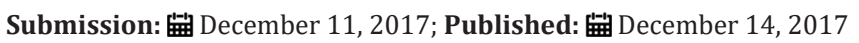

\section{Opinion}

The necessity of measuring all the variables related to training process to understand the improvement of the athlete's performance, has made the quantification of training load (TL) and the study of its relationship with performance raise interest among the scientific community and coaches $[1,2]$. Moreover, with the irruption of new more accessible technology and software, the use of methods to control and quantify the TL have been spread in different sports [3-5]. Furthermore, beyond the improvement of performance perspective, the quantification of the TL can prevent from suffering non-functional overreaching, injuries or illnesses avoiding workload spikes [6-8].

For quantifying the TL there are different variables which can be categorized as either external (watts, speed, etc.) or internal (physiological and psychological). Traditionally, in endurance sports some internal variables have been used to quantify the TL such as heart rate [9-11], blood lactate and Ratings of Perceived Exertion [12,13]. One of the main reasons for that might be based on the necessity of distinguishing and measuring in an individual way the biological stress imposed by a training session in each athlete. The lack of capacity for measuring the internal work with external training quantification methods makes it impossible to compare the different responses of the athletes in a given training session [12]. In last decades several quantifying training proposals based on training zones have emerged as useful methods for monitoring the TL in endurance sports $[2,10,11,14,15]$. By means of these different methods, it is possible to compare intra-inter athletes' TL and the relationship between TL and performance. More recently, it has been confirmed the capacity of comparing different endurance sports by an objective method such as the Cejuela-Anta \& EsteveLanao's [10] ECO system [16].

Table 1: Training zones scores.

\begin{tabular}{|c|c|c|c|c|c|c|c|c|c|c|c|c|c|c|}
\hline \multicolumn{3}{|c|}{ Lucia's TRIMPs } & \multicolumn{3}{|c|}{ Edwards' TRIMPs } & \multicolumn{3}{|c|}{ Stagno's TRIMPs } & \multicolumn{3}{|c|}{ Mujika's training unit } & \multicolumn{3}{|c|}{$\begin{array}{l}\text { Cejuela-Anta \& Esteve- } \\
\text { Lanao's ECOs }\end{array}$} \\
\hline Zone & Intensity & Score & Zone & $\begin{array}{c}\text { Intensity } \\
\text { (HR } \\
\text { Zones \%) }\end{array}$ & Score & Zone & $\begin{array}{c}\text { Intensity(HR } \\
\text { Zones \%) }\end{array}$ & Score & Zone & $\begin{array}{l}\text { Intensity } \\
\text { (Blac) }\end{array}$ & Score & Zone & Intensity & Score \\
\hline 1 & $<\mathrm{AeT}$ & 1 & 1 & $50-60$ & 1 & 1 & $65-71$ & 1.25 & 1 & $<2 \mathrm{mMol}-1$ & 1 & 1 & $<\mathrm{AeT}$ & 1 \\
\hline 2 & AeT-AnT & 2 & 2 & $60-70$ & 2 & 2 & $72-78$ & 1.71 & 2 & $4 \mathrm{mMol} \bullet \mathrm{L}-1$ & 2 & 2 & AeT & 2 \\
\hline 3 & $>\mathrm{AnT}$ & 3 & 3 & $70-80$ & 3 & 3 & $79-85$ & 2.54 & 3 & $\begin{array}{c}>6 \\
\mathrm{mMol} \cdot \mathrm{L}-1\end{array}$ & 3 & 3 & AeT-AnT & 3 \\
\hline & & & 4 & $80-90$ & 4 & 4 & $86-92$ & 3.61 & 4 & $\begin{array}{c}\leq 10 \\
\mathrm{mMol} \bullet \mathrm{L}-1\end{array}$ & 5 & 4 & AnT & 4 \\
\hline & & & 5 & $90-100$ & 5 & 5 & $93-100$ & 5.16 & 5 & $\begin{array}{c}10 \\
\mathrm{mMol} \cdot \mathrm{L}-1\end{array}$ & 8 & 5 & $>\mathrm{AnT}$ & 6 \\
\hline & & & & & & & & & & & & 6 & MAP & 9 \\
\hline & & & & & & & & & & & & 7 & LAC Cap & 15 \\
\hline & & & & & & & & & & & & 8 & LAC Pow & 50 \\
\hline
\end{tabular}

<AeT: Below Aerobic Threshold; AeT: Aerobic Threshold; AeT-AnT: between thresholds; AnT: Anaerobic Threshold; >AnT: between AnT and MAP; MAP: Maximal Aerobic Power; LAC Cap: Lactic Capacity; LAC Pow: Lactic Power or Glycolytic Power; Blac: Blood Lactate Concentration. 
Almost all the training quantification methods in endurance sports use two main variables with the aim of quantifying the workload (Volume and Intensity). The Volume might be measured attending to different variables, normally distance (meters and kilometers) or time (minutes and hours). On the other hand, the Intensity should be measured with any internal variable which, at the same time, is linked with a training zone. In the case of Intensity, it is mandatory to establish prior to quantifying the workload, the ratio of the score assigned per unit of volume to each training zone. The different methods that have been suggested through the diverse studies (based on training zones) use a wide variety in their scores for a same given intensity. Lucía [11] and associates proposed a correspondence of 1, 2 and 3 points per each minute performed in zone 1 (below the aerobic threshold), zone 2 (between aerobic and anaerobic threshold) and zone 3 (beyond anaerobic threshold) respectively. Similarly, proposals based on the Heart Rate (HR) during exercise have been reported [14,15]. However, the ECO system [10] and Mujika's et al. [2] training units discriminate more accurately the different training zones and the score of each one (Table 1).

Although several TL quantification methods have been proposed, all of them have several limitations. Because of that some questions remain unsolved. One of the main important limitations of zones of training quantification is the impossibility to compare continuous and interval training sessions. In other words, it is not possible to establish the density of training between continuous and interval training due to the fact that the ratio between activity and rest in continuous training does not exist. As Cejuela-Anta \& EsteveLanao [10] highlight, it is mandatory to establish a coefficient for continuous workouts which allow the comparison of continuous and interval trainings. Another limiting factor is the score by which the unit of time is multiplied. This score must maintain an inversely proportional relationship with the time limit in each intensity zone [10]. In sum, although the use of a quantification method plays a key role in the training process, different limitation factors remain to be solved for improving this process.

\section{References}

1. Seiler KS, Kjerland GØ (2006) Quantifying training intensity distribution in elite endurance athletes: Is there evidence for an "optimal" distribution? Scand J Med Sci Sports 16(1): 49-56.
2. Mujika I, Busso T, Lacoste L, Barale F, Geyssant, Chatard JC (1996) Modeled responses to training and taper in competitive swimmers. Med Sci Sports Exerc 28(2): 251-258.

3. Cross MJ, Williams S, Trewartha G, Kemp SPT, Stokes KA (2016) The influence of in-season training loads on injury risk in professional rugby union. International Journal of Sports Physiology and Performance 11(3): 350-355.

4. Chambers R, Gabbett TJ, Cole MH, Beard A (2015) The use of wearable micro-sensors to quantify sport-specific movements. Sports Medicine 45(7): 1065-1081.

5. McNamara DJ, Gabbett TJ, Naughton G, Farhart P, Chapman P (2013) Training and competition workloads and fatigue responses of elite junior cricket players. Int J Sports Physiol Perform 8(5): 517-526.

6. Halson SL (2014) Monitoring Training Load to Understand Fatigue in Athletes. Sports Medicine 44(2): 139-147.

7. Killen NM, Gabbett TJ, Jenkins DG (2010) Training loads and incidence of injury during the preseason in professional rugby league players. J Strength Cond Res 24(8): 2079-2084.

8. Windt J, Zumbo BD, Sporer B, MacDonald K, Gabbett TJ (2017) Why do workload spikes cause injuries, and which athletes are at higher risk? Mediators and moderators in workload-injury investigations. British Journal of Sports Medicine 51(13): 993-994.

9. Banister EW, Calvert TW, Savage MV, Bach TA (1975) Systems model of training for athletic performance. Aust J Sports Med 7: 57-61.

10. Cejuela-Anta R, Esteve-Lanao J (2011) Training load quantification in triathlon. Journal of Human Sport and Exercise 6(2): 218-232.

11. Lucía, Hoyos J, Pérez M, Chicharro JL (2000) Heart rate and performance parameters in elite cyclists: a longitudinal study. Med Sci Sports Exerc 32(10): 1777-1782.

12. Mujika Ĩ (2013) The alphabet of sport science research starts with $Q$. International Journal of Sports Physiology and Performance 8(5): 465466.

13. Foster C, Hector LL, Welsh R, Schrager M, Green MA, et al. (1995) Effects of specific versus cross-training on running performance. European Journal of Applied Physiology and Occupational Physiology 70(4): 367372.

14. Edwards S (1993) The heart rate monitor book, Polar Electro Oy New York, USA.

15. Stagno KM, Thatcher R, van Someren KA (2007) A modified TRIMP to quantify the in-season training load of team sport players. Journal of Sports Sciences 25(6): 629-634.

16. Esteve-Lanao J, Moreno-Pérez D, Cardona CA, Larumbe-Zabala E, Muñoz I, et al. (2017) Is marathon training harder than the Ironman training? An ECO-method comparison. Frontiers in Physiology 8(5). 